\title{
Elimination of adsorption effects in the analysis of water-soluble vitamins in pharmaceutical formulations by capillary electrophoresis
}

\author{
Lucas Fotsing, Marianne Fillet, Patrice Chiap, Philippe Hubert, Jacques Crommen* \\ Department of Analytical Pharmaceutical Chemistry, Institute of Pharmacy, University of Liège, CHU, B 36, B-4000 Liège 1, Belgium
}

\begin{abstract}
A tendency to an increase in migration times was observed when different water-soluble vitamins were analysed repeatedly in pharmaceutical preparations by capillary electrophoresis. In order to better understand the origin of this effect, the influence of the vitamins and the excipients, such as cellulose derivatives, was investigated. These studies indicated that the increase in analyte migration times was most probably due to the adsorption of different kinds of constituents to the capillary wall. Different rinsing procedures were tested in order to eliminate these unfavourable effects. A rinse of the capillary with a $25 \mathrm{mM}$ sodium dodecyl sulfate (SDS) solution in the running buffer between successive runs was found to be particularly effective when the analysis was performed by free solution capillary zone electrophoresis (CZE). When the vitamins were determined by micellar electrokinetic chromatography (MEKC) using SDS as surfactant, a short capillary rinse with the running buffer was sufficient to obtain reproducible migration times. The CZE and MEKC methods developed were validated and compared. Both methods could be applied to the determination of water-soluble vitamins in different multivitamin formulations. (C) 1999 Elsevier Science B.V. All rights reserved.
\end{abstract}

Keywords: Pharmaceutical analysis; Adsorption; Validation; Vitamins

\section{Introduction}

Vitamins are available in many pharmaceutical formulations (multivitamin preparations), most of them containing various kinds of excipients. Consequently, the quality control of these complex preparations needs high resolution separation techniques. The use of capillary electrophoresis (CE) for determination of vitamins has been widely described [1-17].

Vitamins were determined in different kinds of pharmaceutical formulations, such as tablets $[6,10-$

\footnotetext{
*Corresponding author. Tel.: +32-4-366-4345; fax: +32-4-3664347.

E-mail address: jcrommen@ulg.ac.be (J. Crommen)
}

13,17], injections [2], syrup and gelatine capsules $[12,16]$, using free solution capillary zone electrophoresis (CZE) [11-12,14,16-17], micellar electrokinetic chromatography (MEKC) [1-4,6-7,1213,17] or microemulsion electrokinetic capillary chromatography (MEEKC) [15].

One of the problems often met in the CE determination of vitamins and other pharmaceuticals in tablets is a progressive increase in analyte migration times related to a decrease of the electroosmotic flow velocity $[11,12,17]$. Furthermore, since in $\mathrm{CE}$, the peak area of an analyte is directly related to its migration time $[18,19]$, any variability in migration times will be reflected in peak areas leading to poor precision $[18,19]$. To cope with this problem, it is necessary to correct the peak area by dividing it by 
the corresponding migration time (peak area normalisation) [18-20]. Besides, several authors [12,21-24] have suggested the use of an internal standard to increase the precision of quantitative results.

In a previous work [17], we have shown the necessity, in some cases, of the simultaneous use of peak area normalisation and internal standardisation to improve method precision.

In this paper, the influence of active ingredients and excipients in pharmaceutical formulations on migration time drift has been studied.

Rinsing sequences in which running buffer containing sodium dodecyl sulfate (SDS) was involved have been investigated. Two CE methods for the determination of water-soluble vitamins using a buffer containing SDS either as rinsing liquid (CZE) or as running buffer (MEKC) have been validated and compared.

Finally, these two methods have been applied to the analysis of commercial multivitamin preparations.

\section{Experimental}

\subsection{Apparatus}

All experiments were performed using a Model ${ }^{3 \mathrm{D}} \mathrm{CE}$ system (Hewlett-Packard, Waldbronn, Germany) equipped with a diode array detection system (DAD), an automatic injector, an autosampler and a temperature control system $\left(15-60^{\circ} \mathrm{C}, \pm 0.1^{\circ} \mathrm{C}\right)$. The $\mathrm{HP}^{3 \mathrm{D}} \mathrm{CE}$ ChEMSTATION software was used for instrument control, data acquisition and data analysis. The $\mathrm{pH}$ of the buffers was adjusted by means of a Delta $345 \mathrm{pH}$ meter (Mettler, Healstead, UK).

\subsection{Chemicals and reagents}

Sodium tetraborate, L-cysteine, nicotinic acid and sodium dodecyl sulfate were obtained from Sigma (St. Louis, MO, USA). Boric acid was purchased from Merck (Darmstadt, Germany). Water was of Milli-Q quality (Millipore, Bedford, MA, USA). Thiamine mononitrate (vitamin B1), riboflavin (vitamin B2), nicotinamide (vitamin B3 or PP), pyridoxine hydrochloride (vitamin B6), ascorbic acid (vita- min C) and calcium pantothenate (vitamin B5) were provided by SMB Technology (Marche-en-Famenne, Belgium). All solutions were filtered through a 0.22$\mu \mathrm{m}$ cellulose acetate membrane (Sartorius, Göttingen, Germany) before use.

\subsection{Electrophoretic technique}

Electrophoretic separations were carried out with uncoated fused-silica capillaries of $48.5 \mathrm{~cm}(40 \mathrm{~cm}$ to the detector) $\times 50 \mu \mathrm{m}$ I.D. (Hewlett-Packard, Palo Alto, CA, USA). Before initial use, the capillary was washed successively with basic solutions (i.e., $1 M$ $\mathrm{NaOH}$ followed by $0.1 M \mathrm{NaOH}$ ), water and running buffer. At the beginning of each working day, the capillary was washed with separation buffer for 10 min. The latter consisted of $0.05 M$ sodium tetraborate (borax) adjusted to $\mathrm{pH} 8.5$ with boric acid for the CZE method and $0.05 M$ sodium tetraborate (borax) adjusted to $\mathrm{pH} 8.5$ with boric acid containing $25 \mathrm{~m} M$ of SDS for the MEKC method. The applied voltage was $25 \mathrm{kV}$ and UV detection was performed at $225 \mathrm{~nm}$ for thiamine, riboflavin, nicotinamide and ascorbic acid, and at $215 \mathrm{~nm}$ for pyridoxine and pantothenic acid. Injections were made using the hydrodynamic mode (1 kPa for $10 \mathrm{~s})$. The capillary was thermostated at $25^{\circ} \mathrm{C}$.

\subsection{Sample preparation}

Using the same proportions of the six water soluble-vitamins as those in the pharmaceutical formulation investigated, standard solutions were first prepared for each calibration level $(n=5)$ by dissolving all vitamins in a $100-\mathrm{ml}$ volumetric flask protected from light and with $50 \mathrm{ml}$ of a $1 \%$ acetic acid solution containing $10 \mathrm{~m} M$ L-cysteine (antioxidant) as dissolution medium. After heating at $65^{\circ} \mathrm{C}$ and shaking for $10 \mathrm{~min}$, a 5-ml volume of the internal standard solution was added to the volumetric flask, unless otherwise stated. The latter was filled to the mark with the dissolution medium after cooling to room temperature. The stock solution of internal standard was prepared by dissolving $300 \mathrm{mg}$ of nicotinic acid in $50 \mathrm{ml}$ of the same dissolution medium. All aqueous standard solutions were then filtered through a $0.22-\mu \mathrm{m}$ cellulose acetate membrane. Before dilution (from 4 to 12 times) in order 
to reach the desired concentration levels for each vitamin in the calibration range (50 to $150 \%$ of the nominal concentrations in the pharmaceutical formulation studied), the resulting standard solution contained $12.52 \mathrm{mg} / \mathrm{ml}$ of ascorbic acid, $3.32 \mathrm{mg} / \mathrm{ml}$ of nicotinamide, $1.18 \mathrm{mg} / \mathrm{ml}$ of pantothenic acid, 0.44 $\mathrm{mg} / \mathrm{ml}$ of pyridoxine, $0.30 \mathrm{mg} / \mathrm{ml}$ of riboflavin and $0.33 \mathrm{mg} / \mathrm{ml}$ of thiamine. The migration order of the vitamins was determined by injecting diluted solutions of each vitamin (six times lower concentrations than those mentioned above) and by spectral comparison.

The same sample preparation procedure was applied to synthetic mixtures of the dosage form excipients (analytical placebos) to which the six vitamins were added in the same proportions as in the pharmaceutical formulation for some experiments.

The multivitamin formulation (tablet) examined in this paper contained the six vitamins in the following amounts: ascorbic acid $(180.0 \mathrm{mg})$, nicotinamide (54.0 mg), calcium pantothenate $(19.5 \mathrm{mg})$, pyridox- ine hydrochloride $(7.2 \mathrm{mg})$, riboflavin $(4.8 \mathrm{mg})$ and thiamine mononitrate $(5.4 \mathrm{mg})$. This formulation also contained the followed excipients: cellulose, silica dioxide, magnesium stearate, stearic acid, povidone, starch, lactose, methylhydroxypropylcellulose, polysorbate 60, paraffin, SDS and opaspray solution (mixture of titane dioxide, hydroxypropylcellulose, yellow orange in water) for a total tablet mass of about $800 \mathrm{mg}$.

\section{Results and discussion}

\subsection{Influence of analytes and excipients on migration time drift}

With three new capillaries from the same batch and the same running buffer, three series of experiments were performed in order to better understand the origin of the migration time drift. On the first capillary, 50 consecutive injections of a mixture of the six water-soluble vitamins in the same pro-

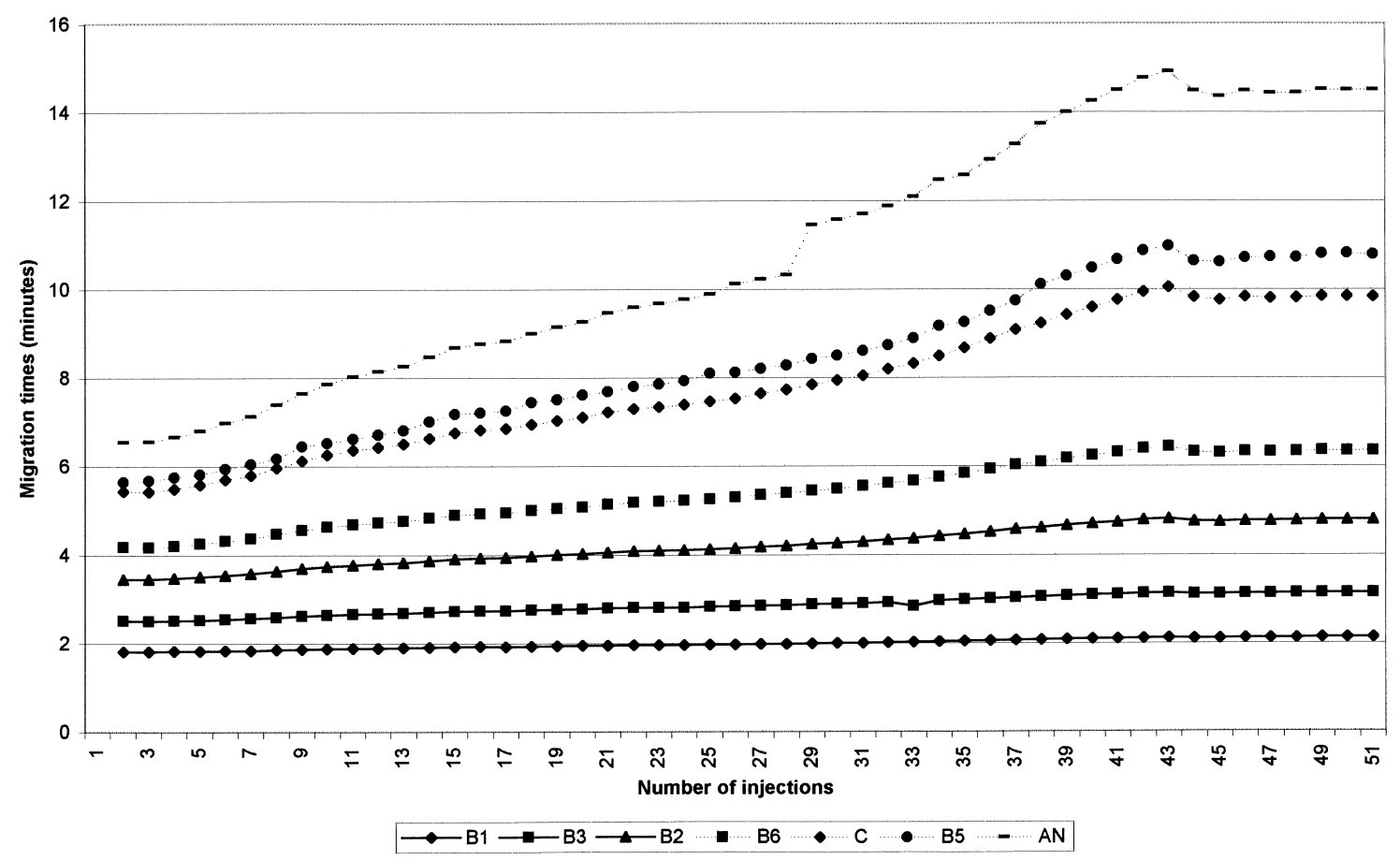

Fig. 1. Changes in migration times with the number of injections (vitamins without excipients: series A). Buffer: $50 \mathrm{~m} M$ borax adjusted to pH 8.5 with boric acid. Rinsing sequence: water for $8 \mathrm{~min}$ and running buffer for $3 \mathrm{~min}$. Other conditions as described in Section 2 . 
portions as in the pharmaceutical formulation were performed (Series A, Fig. 1). Between two runs, the capillary was rinsed with water for $8 \mathrm{~min}$ and running buffer for $3 \mathrm{~min}$. With the second capillary, 50 consecutive injections of a mixture of the six water-soluble vitamins and the excipients in the same proportions as in the pharmaceutical formulation were performed under the same operating conditions as for series A (Series B, Fig. 2). In series A, an increase of migration times was observed, most probably due to the presence of the positively charged thiamine which is likely to interact with the anionic silanol groups on the capillary surface. Indeed, after 50 consecutive injections on the third capillary of a mixture of the water-soluble vitamins except thiamine and without excipients, no significant migration time drift was obtained (Series C, Fig. $3)$. In comparison with series $A$, the increase in migration times observed with series B was clearly more pronounced (Figs. 1 and 2). Among the excipients present in the pharmaceutical formulation, some are soluble in aqueous media, such as cellulose derivatives. During successive runs, these compounds are likely to be adsorbed on the capillary wall, leading to a progressive decrease of the electroosmotic flow and consequently to an increase in migration times.

The variation of migration times is also different for the two series (fairly linear with increasing number of injections for series $\mathrm{A}$ and with several steps for series B).

\subsection{Determination of six water-soluble vitamins in a pharmaceutical formulation}

Using the CZE method [17], several rinsing sequences for reconditioning the capillary between successive injections, involving running buffer to which $25 \mathrm{~m} M$ of SDS was added, water and running buffer with different rinse times, were tested in order to improve the repeatability of migration times. As can be seen in Table 1, acceptable RSD values were only obtained when the rinsing sequence involved the buffer containing SDS. RSD values lower than

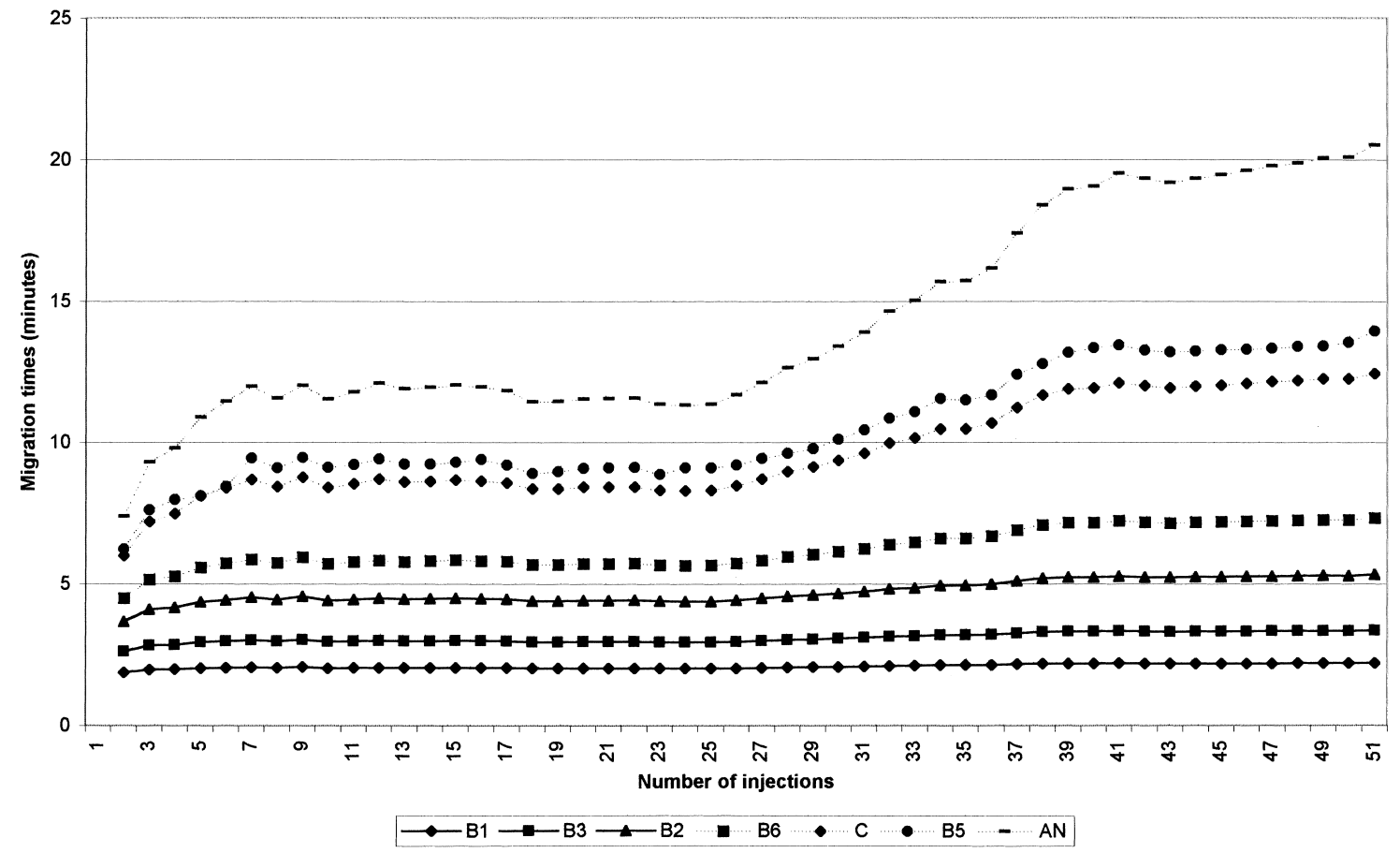

Fig. 2. Changes in migration times with the number of injections (vitamins with excipients: series B). Buffer: $50 \mathrm{~m} M$ borax adjusted to $\mathrm{pH}$ 8.5 with boric acid. Rinsing sequence: water for $8 \mathrm{~min}$ and running buffer for $3 \mathrm{~min}$. Other conditions as described in Section 2 . 


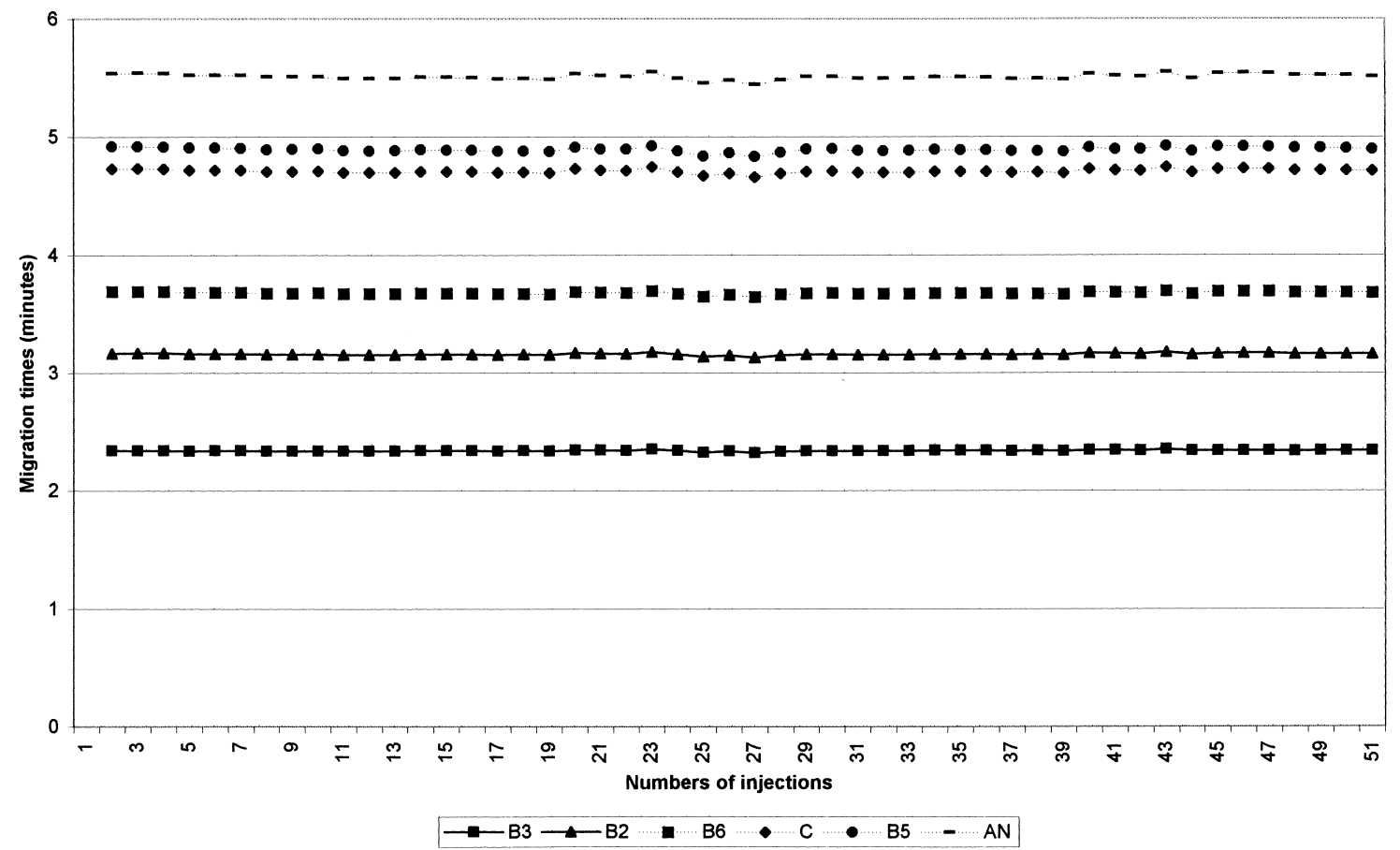

Fig. 3. Changes in migration times with the number of injections (vitamins except thiamine and without excipients: series C). Buffer: 50 $\mathrm{m} M$ borax adjusted to $\mathrm{pH} 8.5$ with boric acid. Rinsing sequence: water for $8 \mathrm{~min}$ and running buffer for 3 min. Other conditions as described in Section 2.

Table 1

CZE: influence of rinsing with buffer containing SDS on migration times repeatability (RSD\%) $(n=10)^{\mathrm{a}}$

\begin{tabular}{|c|c|c|c|c|c|c|}
\hline $\begin{array}{l}\text { Rinsing sequence } \\
\text { (rinse time in min) }\end{array}$ & Thiamine & Nicotinamide & Riboflavin & Pyridoxine & $\begin{array}{l}\text { Ascorbic } \\
\text { acid }\end{array}$ & $\begin{array}{l}\text { Pantothenic } \\
\text { acid }\end{array}$ \\
\hline $\begin{array}{l}\text { Water (4) } \\
\text { Buffer (1) }\end{array}$ & 5.00 & 7.10 & 10.50 & 13.50 & 18.40 & 19.10 \\
\hline $\begin{array}{l}\text { Buffer with SDS (3) } \\
\text { Water (1) } \\
\text { Buffer (1) }\end{array}$ & 0.33 & 0.43 & 0.37 & 0.02 & 0.33 & 0.07 \\
\hline $\begin{array}{l}\text { Buffer with SDS (1) } \\
\text { Water (1) } \\
\text { Buffer (1) }\end{array}$ & 0.33 & 0.40 & 0.30 & 0.17 & 0.61 & 0.53 \\
\hline $\begin{array}{l}\text { Buffer with SDS (1) } \\
\text { Buffer (1) }\end{array}$ & 0.33 & 0.36 & 0.27 & 0.04 & 0.29 & 0.13 \\
\hline
\end{tabular}

\footnotetext{
${ }^{\mathrm{a}}$ Buffer: $50 \mathrm{~m} M$ borax adjusted to $\mathrm{pH} 8.5$ with boric acid; buffer with SDS: $50 \mathrm{~m} M$ borax adjusted to $\mathrm{pH} 8.5$ with boric acid, containing $25 \mathrm{~m} M$ SDS; other conditions as described in Section 2.
} 
Table 2

MEKC: migration times repeatability $(\operatorname{RSD} \%)(n=10)^{\mathrm{a}}$

\begin{tabular}{lllllll}
\hline $\begin{array}{l}\text { Rinsing sequence } \\
\text { (rinse time in min) }\end{array}$ & Thiamine & Nicotinamide & Riboflavin & Pyridoxine & $\begin{array}{l}\text { Ascorbic } \\
\text { acid }\end{array}$ & $\begin{array}{l}\text { Pantothenic } \\
\text { acid }\end{array}$ \\
\hline Running buffer (2) & 0.80 & 0.40 & 0.45 & 0.42 & 0.33 & 0.50 \\
\hline
\end{tabular}

${ }^{a}$ Running buffer: $50 \mathrm{~m} M$ borax adjusted to $\mathrm{pH} 8.5$ with boric acid, containing $25 \mathrm{~m} M$ SDS; other conditions as described in Section 2 .

$0.4 \%$ were found with a rinsing sequence consisting of buffer with $25 \mathrm{~m} M$ of SDS for $1 \mathrm{~min}$, followed by running buffer for $1 \mathrm{~min}$. The latter sequence was selected for further experiments. The introduction of water to the rinsing sequence was found to be superfluous (Table 1). With the MEKC method [17], a rinse with the running buffer which already contained SDS, for 2 min led to RSD values lower than $0.8 \%$ after ten successive injections (Table 2), which were considered satisfactory.

Due to the good repeatability of migration times, peak area normalisation (PN) was found to be unnecessary under the conditions selected. As shown in Table 3, results obtained for the different vitamins in the pharmaceutical formulation in $\mathrm{A}$ and $\mathrm{B}$ on one hand, and in C and D on the other hand, are entirely comparable (the only difference between these series is the use of PN in B and in D). However, the use of an internal standard (I.S.) was still useful. Indeed, some differences can be observed between the results obtained in $\mathrm{A}$ and $\mathrm{C}$ on one hand and in $\mathrm{B}$ and $\mathrm{D}$ on the other hand, the results in $\mathrm{C}$ and $\mathrm{D}$ being slightly superior to those in $\mathrm{A}$ and $\mathrm{B}$ (the only difference between these series is the use of I.S. in C and D). Consequently, conditions for quantification in $\mathrm{C}$ (no $\mathrm{PN}$ and I.S.) were selected and used in validation experiments.

\subsection{Method validation}

\subsubsection{Selectivity}

Selectivity represents the ability to assess the lack of interference originating from others substances present in the matrix. As can be seen from Fig. 4 (CZE method) and Fig. 5 (MEKC method), no interference from the formulation excipients was observed at the migration times of the six vitamins to be determined. The peak homogeneity was confirmed for each vitamin by use of DAD. For each compound, the comparison of various spectra recorded during the passage of the corresponding peak through the detection window led to match scores very close $(>990)$ to the maximum values [25].

\subsubsection{Linearity}

A linear relationship was evaluated over the concentration range of the analytical procedure. For this purpose, calibration curves were constructed at five concentration levels in the range from 50 to $150 \%$ of the nominal concentration and three independent determinations were performed at each concentration $(n=3)$. Regression lines were obtained by plotting the ratios of analyte peak area to that of the internal standard ( $y$, arbitrary units) versus the analyte concentration $(x, \mu \mathrm{g} / \mathrm{ml})$ using the least

Table 3

Percentage of the labelled amounts obtained in a multivitamin formulation by the CZE method ${ }^{\mathrm{a}}$

\begin{tabular}{lllrr}
\hline & \multicolumn{2}{l}{ Percentage labelled amounts } & & \\
\cline { 2 - 5 } & A & B & $101.7 \pm 0.9$ & D \\
\hline Thiamine & $98.8 \pm 2.2$ & $99.1 \pm 1.7$ & $96.9 \pm 2.4$ & $101.7 \pm 1.3$ \\
Riboflavin & $93.7 \pm 2.3$ & $94.1 \pm 2.2$ & $100.4 \pm 0.6$ & $96.8 \pm 1.9$ \\
Nicotinamide & $97.2 \pm 1.5$ & $97.5 \pm 1.9$ & $101.0 \pm 1.0$ & $100.3 \pm 1.0$ \\
Pantothenic acid & $98.4 \pm 1.6$ & $99.3 \pm 1.8$ & $99.2 \pm 1.2$ & $101.1 \pm 1.6$ \\
Pyridoxine & $96.4 \pm 2.0$ & $96.8 \pm 1.6$ & $98.6 \pm 0.7$ & $99.2 \pm 1.3$ \\
Ascorbic acid & $95.5 \pm 1.1$ & $95.8 \pm 1.5$ & $98.7 \pm 0.9$ \\
\hline
\end{tabular}

\footnotetext{
${ }^{\mathrm{a}}$ Buffer: $50 \mathrm{mM}$ borax adjusted to $\mathrm{pH} 8.5$ with boric acid. Other conditions as described in Section 2; (A) no PN and no I.S.; (B) PN and
} no I.S.; (C) no PN and I.S.; (D) PN and I.S.; PN: peak area normalisation; I.S.: internal standard (nicotinic acid). 


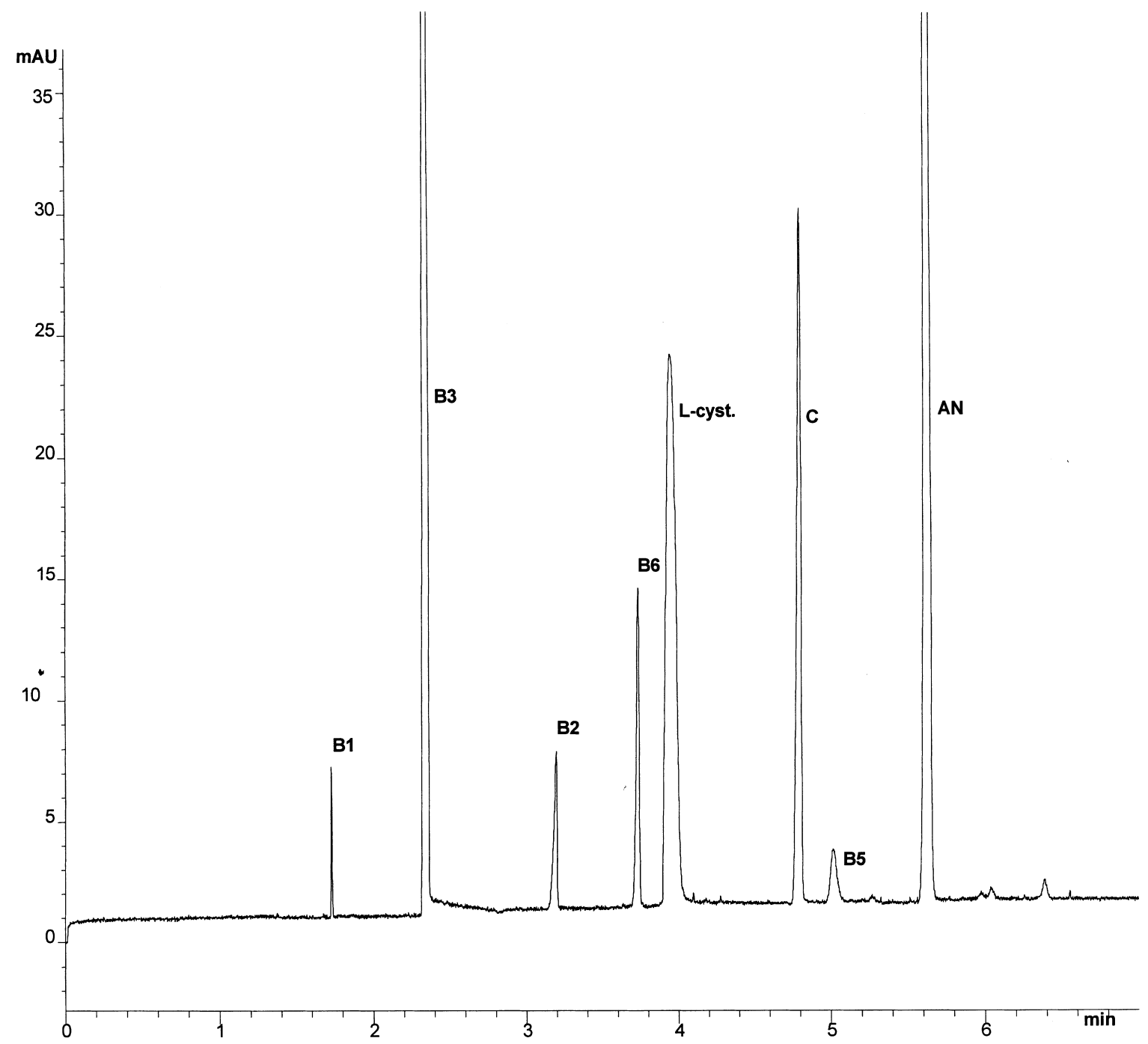

Fig. 4. CZE separation of six vitamins in a pharmaceutical formulation Buffer: $50 \mathrm{~m} M$ borax adjusted to pH 8.5 with boric acid. Rinsing sequence: buffer with $25 \mathrm{mM}$ of SDS for $1 \mathrm{~min}$ and running buffer for $1 \mathrm{~min}$. Detection wavelength: $215 \mathrm{~nm}$. Other conditions as described in Section 2.

squares method. The linearity of the calibration curves for the six vitamins in aqueous solutions (standard solutions) was first assessed. For each vitamin, the relationship between response and concentration was found to be linear in the concentration range considered. In all cases, straight lines passing through the origin with coefficients of determination $\left(r^{2}\right)$ higher than 0.999 were obtained. However, the application of the usual least squares model implies that the variance of the response is constant over the concentration range considered (homoscedasticity hypothesis). The validity of this hypothesis was confirmed by use of Cochran's test [26,27]. The adequacy of the model was then assessed by use of a lack of fit test, the $F$ values obtained being lower than the critical $F$ value of the table [26,27].

The same statistical approach was then applied to a synthetic mixture of the excipients of the dosage form to which known quantities of each vitamin were added (spiked placebos), corresponding to the 


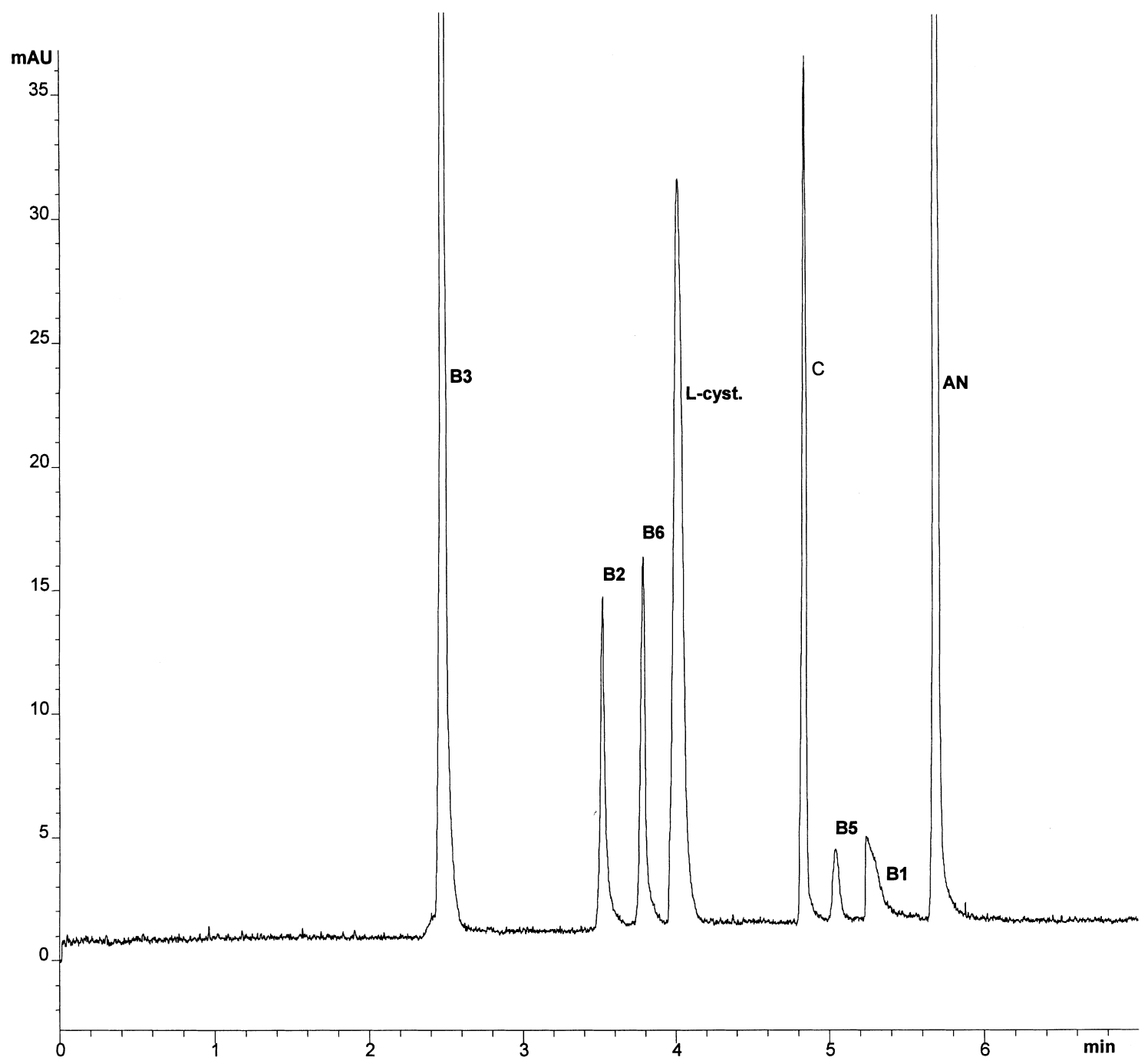

Fig. 5. MEKC separation of six vitamins in a pharmaceutical formulation. Buffer: $50 \mathrm{~m} M$ borax adjusted to $\mathrm{pH} 8.5$ with boric acid containing $25 \mathrm{mM}$ of SDS. Rinsing sequence: running buffer for $2 \mathrm{~min}$. Detection wavelength: $215 \mathrm{~nm}$. Other conditions as described in Section 2.

different concentration levels in the range tested. The regression parameters are given in Table 4 (CZE) and Table 5 (MEKC). As described above, the regression lines were obtained by use of the least squares method following the hypothesis of homoscedasticity [27,28]. All regression lines were found to pass through the origin with $t_{\text {calc }}<2.16$ ( $P=$ $0.05)$. In all cases, the linearity of the calibration graphs was demonstrated by the high determination coefficients obtained for the regression lines and confirmed by an analysis of variance (ANOVA) test. The adequacy of the selected regression model to describe the relationship between $y$ and $x$ (lack of fit test) was assessed with $F_{\text {calc }}<3.71(P=0.05)$ for all vitamins. Finally, the slopes and intercepts of the regression lines for standards and spiked placebos, respectively, were found to be not significantly different, with $t_{\text {calc }}<2.05(P=0.05)$ for each vitamin. From the results of these statistical tests, it can be concluded that in the operating conditions de- 
Table 4

CZE: linearity and accuracy (spiked placebos)

\begin{tabular}{|c|c|c|c|c|c|c|}
\hline & Thiamine & Nicotinamide & Riboflavin & Pyridoxine & $\begin{array}{l}\text { Ascorbic } \\
\text { acid }\end{array}$ & $\begin{array}{l}\text { Pantothenic } \\
\text { acid }\end{array}$ \\
\hline \multicolumn{7}{|c|}{ Linearity } \\
\hline \multicolumn{7}{|c|}{ Regression parameters } \\
\hline$r^{2}$ & 0.9990 & 0.9990 & 0.9994 & 0.9993 & 0.9992 & 0.9991 \\
\hline Intercept $\left(10^{-3}\right)$ & 0.4 & -7.5 & 0.9 & -0.2 & -8.8 & 0.3 \\
\hline Slope $\left(10^{-3}\right)$ & 1.6 & 1.3 & 2.0 & 1.2 & 0.3 & 0.2 \\
\hline \multicolumn{7}{|c|}{ Accuracy: mean recovery \pm C.I. (\%) } \\
\hline \multicolumn{7}{|c|}{ Concentration levels $(\%)$} \\
\hline 50 & $100.4 \pm 1.9$ & $100.2 \pm 0.7$ & $99.6 \pm 1.7$ & $101.3 \pm 0.8$ & $99.6 \pm 1.0$ & $100.6 \pm 2.9$ \\
\hline 100 & $99.7 \pm 1.0$ & $99.8 \pm 1.6$ & $101.1 \pm 1.9$ & $100.0 \pm 1.1$ & $99.9 \pm 1.3$ & $101.1 \pm 0.9$ \\
\hline 150 & $99.8 \pm 0.4$ & $100.0 \pm 0.6$ & $99.6 \pm 1.3$ & $99.8 \pm 0.9$ & $100.6 \pm 0.8$ & $99.4 \pm 1.2$ \\
\hline
\end{tabular}

Table 5

MEKC: linearity and accuracy (spiked placebos)

\begin{tabular}{|c|c|c|c|c|c|c|}
\hline & Thiamine & Nicotinamide & Riboflavin & Pyridoxine & $\begin{array}{l}\text { Ascorbic } \\
\text { acid }\end{array}$ & $\begin{array}{l}\text { Pantothenic } \\
\text { acid }\end{array}$ \\
\hline \multicolumn{7}{|l|}{ Linearity } \\
\hline \multicolumn{7}{|c|}{ Regression parameters } \\
\hline$r^{2}$ & 0.9993 & 0.9991 & 0.9993 & 0.9991 & 0.9992 & 0.9991 \\
\hline Intercept $\left(10^{-3}\right)$ & 1 & 4.8 & 1.6 & 0.04 & -0.9 & 0.4 \\
\hline Slope $\left(10^{-3}\right)$ & 1.5 & 1.2 & 2.1 & 1.1 & 0.3 & 0.1 \\
\hline \multicolumn{7}{|c|}{ Accuracy: mean recovery \pm C.I. (\%) } \\
\hline \multicolumn{7}{|c|}{ Concentration levels $(\%)$} \\
\hline 50 & $101.3 \pm 2.0$ & $100.9 \pm 2.4$ & $99.8 \pm 2.0$ & $100.5 \pm 2.4$ & $100.7 \pm 0.8$ & $99.0 \pm 2.8$ \\
\hline 100 & $99.6 \pm 1.0$ & $99.8 \pm 1.4$ & $99.7 \pm 1.5$ & $100.7 \pm 1.0$ & $99.4 \pm 1.2$ & $101.0 \pm 1.8$ \\
\hline 150 & $100.2 \pm 1.1$ & $100.0 \pm 0.3$ & $99.7 \pm 0.6$ & $99.6 \pm 1.4$ & $99.5 \pm 1.6$ & $99.1 \pm 1.5$ \\
\hline
\end{tabular}

scribed above, there is no matrix effect, even for nicotinamide in CZE, which migrates with the electroosmotic flow, and a single-level calibration corresponding to the labelled amount of each vitamin could be used in routine analysis. There are no significant differences between the results obtained with CZE and MEKC methods (Tables 4 and 5).

\subsubsection{Accuracy}

Accuracy was assessed over the whole concen-

Table 6

CZE: precision (spiked placebos)

\begin{tabular}{|c|c|c|c|c|c|c|}
\hline $\begin{array}{l}\text { Concentration } \\
\text { levels }(\%)\end{array}$ & Thiamine & Nicotinamide & Riboflavin & Pyridoxine & $\begin{array}{l}\text { Ascorbic } \\
\text { acid }\end{array}$ & $\begin{array}{l}\text { Pantothenic } \\
\text { acid }\end{array}$ \\
\hline \multicolumn{7}{|c|}{ Repeatability $(k=3, n=6$, RSD $\%)$} \\
\hline 50 & 1.6 & 1.8 & 2.0 & 2.1 & 1.0 & 3.1 \\
\hline 100 & 1.3 & 1.0 & 1.4 & 1.1 & 0.9 & 2.4 \\
\hline 150 & 1.0 & 0.8 & 0.9 & 1.0 & 0.8 & 2.0 \\
\hline \multicolumn{7}{|c|}{ Intermediate precision $(k=3, n=6, \mathrm{RSD} \%)$} \\
\hline 50 & 2.9 & 3.0 & 3.0 & 2.6 & 2.4 & 4.3 \\
\hline 100 & 1.8 & 1.6 & 1.9 & 1.7 & 2.2 & 2.6 \\
\hline 150 & 1.0 & 1.2 & 1.2 & 1.3 & 1.6 & 2.0 \\
\hline
\end{tabular}


tration range (50, 100 and $150 \%)$ by analysing placebos spiked with the six vitamins at three concentration levels $(n=6)$. Mean recoveries with 95\% confidence intervals (C.I.) are given in Table 4 (CZE) and Table 5 (MEKC). With both methods, satisfactory results with respect to accuracy were obtained for the six vitamins. The maximum experimental bias for each point is lower than $1.8 \%$ which is an acceptable value for an active ingredient in a pharmaceutical formulation. The two methods can therefore be considered as accurate over the range investigated. No significant differences were observed between the results obtained with CZE and MEKC methods (Tables 4 and 5).

\subsubsection{Precision}

As can be seen in Table 6 (CZE) and Table 7 (MEKC), precision was determined by measuring repeatability and intermediate precision (betweenday precision) for each vitamin in spiked placebos $(n=6)$. This study was carried out for 3 days $(k=3)$ at the same three concentration levels $(50,100$ and $150 \%$ ). The RSD values were estimated from repeatability and time-different intermediate precision variances, respectively [27,28]. Satisfactory results with respect to precision were obtained for all vitamins studied.

\subsection{Quantitative analysis of vitamins in several commercial multivitamin preparations}

The water-soluble vitamins contained in four
Table 8

Determination of six vitamins in commercial preparations ${ }^{a}$

\begin{tabular}{|c|c|c|c|}
\hline \multirow[t]{2}{*}{ Sample } & \multirow{2}{*}{$\begin{array}{l}\text { Analyte } \\
\text { (labelled } \\
\text { amounts, mg) }\end{array}$} & \multicolumn{2}{|c|}{$\begin{array}{l}\text { Percent of the labelled } \\
\text { amount (average } \pm \text { SD) }\end{array}$} \\
\hline & & CZE & MEKC \\
\hline \multirow[t]{6}{*}{ Tablet $1^{\mathrm{b}}$} & B1 (4.2) & $101.7 \pm 0.9$ & $101.3 \pm 1.6$ \\
\hline & B2 (4.8) & $96.9 \pm 2.4$ & $97.1 \pm 1.6$ \\
\hline & B3 (54.0) & $100.4 \pm 0.6$ & $100.2 \pm 1.1$ \\
\hline & B5 (18.0) & $101.0 \pm 1.0$ & $100.9 \pm 1.4$ \\
\hline & B6 (6.0) & $99.2 \pm 1.2$ & $99.6 \pm 1.6$ \\
\hline & C (180.0) & $98.6 \pm 0.7$ & $99.2 \pm 0.9$ \\
\hline \multirow[t]{6}{*}{ Tablet 2} & B1 (1.2) & $97.8 \pm 1.3$ & $98.2 \pm 1.7$ \\
\hline & B2 (1.8) & $95.4 \pm 1.9$ & $96.1 \pm 2.3$ \\
\hline & B3 (19.0) & $99.2 \pm 0.7$ & $98.9 \pm 1.3$ \\
\hline & B5 (9.2) & $98.6 \pm 1.3$ & $98.4 \pm 1.9$ \\
\hline & B6 (2.2) & $99.2 \pm 1.8$ & $99.6 \pm 2.1$ \\
\hline & C (100) & $98.2 \pm 1.0$ & $98.6 \pm 1.2$ \\
\hline \multirow[t]{3}{*}{ Tablet 3} & B1 (195.2) & $100.9 \pm 0.9$ & $100.7 \pm 2.2$ \\
\hline & B2 (10.0) & $99.3 \pm 2.1$ & $99.5 \pm 1.8$ \\
\hline & B6 (208.3) & $100.2 \pm 1.6$ & $100.2 \pm 1.4$ \\
\hline \multirow[t]{6}{*}{ Tablet 4} & B1 (2.8) & $98.4 \pm 1.1$ & $98.1 \pm 1.4$ \\
\hline & B2 (3.2) & $97.1 \pm 2.2$ & $97.4 \pm 1.7$ \\
\hline & B3 (36.0) & $100.6 \pm 0.8$ & $100.9 \pm 1.1$ \\
\hline & B5 (12.0) & $98.7 \pm 1.7$ & $98.6 \pm 1.4$ \\
\hline & B6 (2.0) & $97.8 \pm 1.8$ & $97.5 \pm 2.2$ \\
\hline & C (180.0) & $101.4 \pm 1.2$ & $101.6 \pm 0.9$ \\
\hline
\end{tabular}

${ }^{\mathrm{a}}$ CZE: Buffer: $50 \mathrm{~m} M$ borax adjusted to $\mathrm{pH} 8.5$ with boric acid; rinsing sequence: buffer with $25 \mathrm{~m} M$ of SDS for 1 min and running buffer for $1 \mathrm{~min}$; no PN and I.S.; MEKC: Buffer: $50 \mathrm{mM}$ borax adjusted to $\mathrm{pH} 8.5$ with boric acid, containing $25 \mathrm{mM}$ of SDS; rinsing sequence: running buffer for $2 \mathrm{~min}$; no PN and I.S.; other conditions as described in Section 2.

${ }^{\mathrm{b}}$ CZE results are those presented in Table $3(\mathrm{C})$.

Table 7

MEKC: precision (spiked placebos)

\begin{tabular}{|c|c|c|c|c|c|c|}
\hline $\begin{array}{l}\text { Concentration } \\
\text { levels }(\%)\end{array}$ & Thiamine & Nicotinamide & Riboflavin & Pyridoxine & $\begin{array}{l}\text { Ascorbic } \\
\text { acid }\end{array}$ & $\begin{array}{l}\text { Pantothenic } \\
\text { acid }\end{array}$ \\
\hline \multicolumn{7}{|c|}{ Repeatability $(k=3, n=6$, RSD $\%)$} \\
\hline 50 & 1.7 & 1.6 & 1.8 & 2.0 & 1.0 & 2.9 \\
\hline 100 & 1.5 & 1.3 & 1.3 & 1.2 & 0.8 & 2.1 \\
\hline 150 & 0.9 & 0.5 & 0.8 & 1.6 & 0.7 & 1.8 \\
\hline \multicolumn{7}{|c|}{ Intermediate precision $(k=3, n=6, \mathrm{RSD} \%)$} \\
\hline 50 & 3.1 & 2.6 & 3.0 & 3.0 & 2.4 & 4.2 \\
\hline 100 & 1.7 & 1.3 & 1.5 & 1.2 & 2.0 & 2.4 \\
\hline 150 & 0.9 & 1.2 & 0.8 & 1.7 & 1.1 & 1.9 \\
\hline
\end{tabular}


different commercial tablet formulations were quantified using the CZE and MEKC methods described above. The results are given in Table 8 . Tablet 1 corresponds to the formulation the composition of which is given in Section 2. Although the peak of thiamine was not very symmetrical in MEKC, most probably because of electrostatic interactions between this positively charged vitamin and the anionic surfactant, its quantification did not cause any particular problem. In all cases, the results obtained with the MEKC method are comparable to those obtained in CZE.

\section{References}

[1] D.E. Burton, M.J. Sepaniak, M.P. Maskarinec, J. Chromatogr. 24 (1986) 347.

[2] S. Fujiwara, S. Iwase, S. Honda, J. Chromatogr. 447 (1988) 133.

[3] H. Nishi, N. Tsumagari, T. Kakimoto, S. Terabe, J. Chromatogr. 465 (1989) 331.

[4] S. Kobayashi, T. Ueda, M. Kikumoto, J. Chromatogr. 480 (1989) 179.

[5] E. Kenndler, C. Schwer, D. Kaniansky, J. Chromatogr. 508 (1991) 203.

[6] C.P. Ong, C.L. Ng, H.K. Lee, S.F.Y. Li, J. Chromatogr. 547 (1991) 419.

[7] Y.F. Yik, H.K. Lee, S.F.Y. Li, S.B. Khoo, J. Chromatogr. 585 (1991) 139.

[8] D. Lambert, C. Adjalla, F. Felden, S. Benhayoun, J.P. Nicolas, J.L. Gueant, J. Chromatogr. 608 (1992) 311.
[9] E.V. Koh, M.G. Bisell, R.K. Ito, J. Chromatogr. 633 (1993) 245.

[10] R. Huopalathi, J. Sunell, J. Chromatogr. 636 (1993) 133.

[11] U. Jegle, J. Chromatogr.A 652 (1993) 495.

[12] S. Boonkerd, M.R. Detaevernier, Y. Michotte, J. Chromatogr. A 670 (1994) 209.

[13] G. Dinelli, A. Bonetti, Electrophoresis 15 (1994) 1147.

[14] H.L. Shi, Y.F. Ma, J.H. Humphrey, N.E. Craft, J. Chromatogr. B 665 (1995) 89.

[15] R.L. Boso, M.S. Bellini, I. Miksik, Z. Deyl, J. Chromatogr. A 709 (1995) 11.

[16] J. Schiewe, S. Gobel, M. Schwarz, R. Neubert, J. Pharm. Biomed. Anal. 14 (1996) 435.

[17] L. Fotsing, M. Fillet, I. Bechet, Ph. Hubert, J. Crommen, J. Pharm. Biomed. Anal. 15 (1997) 1113.

[18] K.D. Altria, Chromatographia 35 (1993) 177.

[19] K.D. Altria, in: Analysis of Pharmaceuticals By Capillary Electrophoresis, Chromatographia CE Series, Vol. 2, Vieweg, Wiesbaden, 1998.

[20] T. Ackermans, F.M. Everaerts, J.L. Beckers, J. Chromatogr. 549 (1991) 345.

[21] A.M. Hoyt Jr., M.J. Sepaniak, Anal. Lett. 22 (1989) 861.

[22] M.E. Swartz, J. Liq. Chromatogr. 14 (1991) 923.

[23] E.V. Dose, G.A. Guiochon, Anal. Chem. 63 (1991) 1154.

[24] E.W. Tsai, M.H. Singh, H.H. Lu, D.P. Ip, M.A. Brooks, J. Chromatogr. 626 (1992) 245.

[25] H.-J.P. Sievert, A.C.J.H. Drouen, Diode Array Detection in HPLC, Marcel Dekker, New York, 1993.

[26] D.L. Massart, B.G.M. Vandeginste, S.N. Deming, Y. Michotte, L. Kaufman, Chemometrics: A Textbook, Elsevier, Amsterdam, 1988.

[27] J. Caporal-Gautier, J.M. Nivet, P. Algranti, M. Guilloteau, M. Histe, M. Lallier, J.J. N'Guyen-Huu, R. Russotto, S.T.P. Pharma Pratiques 2 (1992) 202.

[28] C. Hartmann, Analysis 22 (1994) M19-M20. 